\title{
Biotechnology mergers and acquisitions
}

\section{Consolidation strategies from within biotechnology are necessary to preserve the future financing of the industry.}

\author{
Farah H. Champsi \\ During the last two decades, the \\ biotechnology revolution has result- \\ ed in phenomenal advances in the \\ understanding and treatment of \\ many diseases. While replacement \\ proteins such as erythropoietin and \\ tissue plasminogen activator were \\ While there are more companies than \\ ever being funded as startups, the \\ bar has been raised for what investors \\ are willing to pay when taking these \\ companies public.
} the first products to validate the promise of the biotechnology industry, the industry now uses everything from monoclonal antibodies to small molecules to create blockbuster products for the biopharmaceutical industry. To date, this industry has produced 75 commercialized products, and 35 more are slated for FDA approval in 1998.

Both the breadth and the depth of the approaches that biotechnology has produced are possible because of the inestimable amount of capital that has poured into this sector over the last 20 years. However, there are two seemingly contradictory trends in the financial markets at present that, we believe, biotechnology companies must successfully reconcile if they are to continue to raise money.

On the one hand, public investors are becoming more savvy about the risks associated with biotechnology, and are demanding more performance for their investment dollars. At the same time, a new, scientifically educated class of venture capitalists has emerged whose enthusiasm for biotechnology has spawned an unprecedented amount of venture capital investment in this industry. While there are more companies than ever being funded as startups, the bar has been raised for what investors are willing to pay when taking these companies public.

Since venture capitalists typically need to take these startups public to raise additional capital and to recoup their investments, the questions before the biotechnology industry are, "How can small private companies make the transition to the initial public offering without disappointing the venture capital

Farah $\mathrm{H}$. Champsi is managing director and head of life sciences investment banking at BancAmerica Robertson Stephens, 555 California Street, San Francisco CA 94104. The views and opinions are those of the author and do not necessarily reflect the views and opinions of BancAmerica Robertson Stephens. community?" and, more importantly, if they can go public, "How can public companies sustain investor confidence and build value?"

The pharmaceutical industry has recently provided the financial community with a business model based on mergers and acquisitions that has received widespread support. While the biotechnology industry does not have the same reasons for entering into merger and acquisition activity, public market investors are demanding risk-diversification strategies from biopharmaceutical companies. Investors are concentrating their holdings in companies with "critical mass," requiring them to pursue $M \& A$ as a requisite

\section{The state of the investor- biotechnology union}

Today, there are approximately 300 public and 1,000 private biopharmaceutical companies in the US alone. In Europe, there are 32 public companies and 260 private companies. Since 1991, over $\$ 29$ billion has been raised by the industry to fund research from public market investors. So far, however, only a dozen companies have crossed the billiondollar market value threshold, and even fewer have generated profits from product sales.

What can we say about the way the market views biotechnology's potential to produce more of these blockbuster billion-dollar drugs? In 1997, 16 biopharmaceutical companies went public, raising approximately $\$ 500$ million, and gaining an average of $14.9 \%$ during the year, compared to the S\&P 500 index price appreciation of $31.7 \%$. In contrast, 27 biopharmaceutical companies completed follow-on offerings, raising \$1.4 billion, typically for later-stage products.

From these data, it has become clear that companies with late-stage clinical stories or products nearing market launch such as to future financing and liquidity.
MedImmune (Gaithersburg, MD), COR (S. San Francisco, CA), and Aviron (Mountain View, CA) are getting the lion's share of the funding. Earlier stage and "platform" technology companies such as Corixa (Seattle, WA), Hyseq (Sunnyvale, CA), and Progenitor (Columbus,

$\mathrm{OH}$ ) generally are not being favorably perceived by the market because investors are skeptical that the product technologies or approaches offered by these types of companies will generate near-term revenues or be sufficient to attract the premier pharmaceutical partners. As a result, most of these companies are trading below their IPO prices.

There appears to be no shortage of venture capital flowing into the biopharmaceutical sector, with $\$ 950$ million invested in 1997, a $46 \%$ increase over 1996. Most of this was directed toward novel technologies and tools that can capitalize on the genomics revolution's promise to reduce the time, expense, and risk of conventional drug discovery. Venture capitalists are pushing biotechnology with the tools of information technology: miniaturization, speed, software, and instrumentation. Yet most of these companies will not reach the scale and integration required to be publicly funded.

\section{Sustaining investor expectations}

With the failure of most companies to deliver products to the clinic, or even to reach the critical mass necessary for public funding, investors are reexamining the basic premise of biotechnology's attraction for the financial community: Biotechnology has always promised that it could develop new products that are financially meaningful and that it could reduce the risks and expenses associated with such product development.

In the case of billion-dollar biotechnology drugs, this has proven to be true, but for the vast majority of companies, drug development has been as predictable as playing roulette. Think back for a moment to the experiences of Synergen (Boulder, CO), ImmuLogic (Waltham, MA), AutoImmune (Lexington, MA), and countless others that have battled the odds. With more than 100 public companies in early human trials, how is the investor 
to decide which will deliver on biotechnology's promise? All these companies have market values of less than $\$ 300$ million and all are using technologies such as antibodies, small molecules, peptides, gene therapy, or vaccines against HIV, cancer, and inflammatory and cardiovascular diseases. Most investors cannot differentiate between most of these companies, and consequently, they ignore them until meaningful phase III data are available.

Furthermore, it is not clear whether the path for a biopharmaceutical company today is getting easier, now that the focus of drug therapy has shifted away from treating symptoms to understanding the genetic basis of disease. Many of the new companies in biotechnology are advancing the tools and techniques required to conduct gene-based drug discovery. But it is far more difficult to develop therapeutics based on genomics than on conventional approaches. The challenge of linking diseases to gene targets, then linking gene targets to therapeutic targets, and then validating therapeutic targets for final selection as clinical candidates requires whole new approaches to drug discovery. Yet there is no question that genetics is the key to unraveling therapeutics to many underserved diseases.

How, then, will the industry sustain itself and ensure the support of its public investors, when it appears that the more we learn, the less we can predict about the challenges of drug discovery and development?

\section{Product mergers and acquisitions}

Given the burgeoning number of startups and the diminishing amount of public dollars, the future of the industry will depend on the survival of the fittest. Only those companies that can deliver on the goals of return on investment, diversification of risk, and development of critical mass to realize meaningful financial upside will remain.

It is inevitable that the total number of public companies will diminish. Undoubtedly, some of this will occur through outright failures. However, a more favorable outcome for the industry can be achieved through an industry-wide acceptance of the need for consolidation and the strategic negotiation of biotech-to-biotech mergers and acquisitions. Such historical impediments to M\&A activity as demands for inflated prices, wounded egos, geographic barriers, and increased burn rate should be discarded in favor of building longterm value and reducing risk.

So far, product-based and clinical trial stage companies have been reluctant to conduct mergers and acquisitions, primarily because of concerns about diluting their focus or risking equity dilution to acquire products that have uncertain potential. However, we believe these companies are precisely the ones that need to use mergers and acquisitions strategies for risk diversification through development of com- plementary products and technologies. Success stories that have taken the initiative in this regard include Alkermes (Cambridge, MA) and Chiron (Emeryville, CA), and more recently, younger companies such as Allelix's (Mississauga, Canada) 1997 acquisition of privately held Trophix (S. Plainfield, NJ) to gain access to more neuroscience product candidates, and Triangle's (Durham, NC) purchase of Avid (Philadelphia, PA) later in that year to get additional anti-HIV compounds. In 1998, Neurocrine (San Diego, CA) announced the purchase of private Northwest Neurologic (Portland, OR) to gain additional central nervous system technology.

For product-based companies facing difficult financing markets, finding merger partners or acquisition candidates is a way to breathe new life into the company. Using trades of stock-for-stock to finance these deals, especially during times when stocks are depressed and investors are apathetic, enables companies to build long-term value cost effectively. For companies that win the support of investors, the opportunity for a mergers and acquisitions activity can be used as a catalyst to raise additional capital more easily, as was demonstrated by Shire Pharmaceuticals (Hampshire, UK), which recently completed a successful NASDAQ initial public offering based on its acquisition of Pharmavene (Rockville, MD) and Richwood Pharmaceuticals (Florence, KY).

\section{Platform to platform}

The second area of biotechnology in which mergers and acquisitions activity is already proving to be important is in platform companies seeking other platforms to enhance their value to the pharmaceutical industry. Since most major pharmaceutical companies want a comprehensive, reproducible solution to their urgent need for new drug targets, one alternative is to merge these companies in order to create the value sought by large pharma. The ideal biopharmaceutical company will be able to deliver a lead compound based on a rational, integrated approach of gene discovery and target validation, combining the best of biology, chemistry, and informatics.

It is clear that the savviest platform companies have already figured out the benefits of this strategy. In late 1996, ChiroScience (Cambridge, UK) acquired privately held Darwin (Seattle, WA), in an effort to marry its chemistry skills with genomics. In 1997, Millennium (Cambridge, MA) picked up ChemGenics (Cambridge, MA) to gain fungal biology and chemistry expertise and Arris (S. San Francisco, CA) merged with Sequana (La Jolla, CA) to integrate genomics with its drug discovery capabilities. In addition, we saw other companies such as Incyte (Palo Alto, CA) and Perkin Elmer (Norwalk, CT) reinvent themselves by moving aggressively into new technologies to remain competitive in the genomics area by acquiring Synteni (Fremont, CA) and Molecular Informatics (Santa Fe, NM), respectively. In 1998, the pace has accelerated, with numerous discussions underway. Pharmacoepia's (Princeton, NJ) acquisition of MSI (San Diego, CA), the first of several platform mergers that should occur this year, combines its established chemistry platform with software capability.

While the true synergies of many of these transactions still remain to be realized, it is obvious that investors are generally willing to be convinced and will applaud these combinations, provided they appear to build on core competencies, increase revenue potential significantly, and reduce the risk of failure, because all of these activities are seen as ways to accelerate the path to building large, profitable companies.

This message has not been lost on private biopharmaceutical companies. In the past year, for example, Tularik (S. San Francisco, CA) acquired Amplicon (Stony Brook, NY), PowderJect (Oxford, UK) acquired Auragen (Middleton, WI), and Exelixis (S. San Francisco, CA) helped form and acquired a piece of German-based Artemis. Each of these transactions was designed to increase the long-term value of the companies to investors. PowderJect is the most recent beneficiary of this strategy, with its $\$ 300+$ million deal on Auragen's technology with Glaxo Wellcome (London) announced last month. PowderJect's stock price increased $61 \%$ following its announcement that it was collaborating on several DNA vaccines with Glaxo.

\section{Conclusions}

As the biotechnology industry moves further into the uncharted territory of drug discovery, it must make convincing arguments for investors to follow. While public investors no longer have the confidence to routinely invest in emerging life sciences companies, we believe those companies that can show the determination to produce either multiple therapeutic product "quivers" or integrated platform solutions for drug discovery will still attract funding.

Over the next several years, we believe M\&A activity will be a crucial strategy for accomplishing these goals. Since the IPO market will not accept companies that can not compete at this level, it will be up to the venture capital community and hardened institutional investors to instigate mergers and acquisitions activity between private biotechnology companies as well as public biotechnology companies.

If these plans are successfully implemented, we believe the biopharmaceutical industry can look forward to success in R\&D through risk diversification and mainstream acceptance in the public markets for its pioneering efforts into new products, genomics, and other novel drug discovery technologies. /// 